\title{
PONTO DE PARTIDA: ALIMENTANDO DIÁLOGOS, REFLEXÕES E INTERVENÇÕES EDUCATIVAS NO ALTO DO MOURA, ACERCA DAS DIVERSIDADES, NA PERSPECTIVA DA DIFERENÇA E DA INTERSECCIONALIDADE
}

\author{
STARTING POINT: FEEDING DIALOGUES, REFLECTIONS AND \\ EDUCATIONAL INTERVENTIONS IN ALTO DO MOURA, ABOUT
} DIVERSITIES, FROM THE PERSPECTIVE OF DIFFERENCE AND INTERSECTIONALITY

\author{
Maria do Carmo Gonçalo Santos ${ }^{1}$ \\ Everaldo Fernandes da Silva ${ }^{2}$
}

\section{RESUMO}

Este artigo, fruto de um trabalho educativo do grupo "Ponto de Partida", desenvolvido na Comunidade do Alto do Moura, em Caruaru-PE, trata dos diálogos, reflexões e intervenções acerca das diferenças. Situamos a diferença enquanto rede de relações para o enfrentamento das desigualdades, que se configuram a partir de estruturas de poder interseccionais, que envolvem gênero, classe, raça, geração e religião. $\mathrm{O}$ texto apresenta o desenvolvimento de um trabalho de extensão que articula sujeitos, espaços formativos e saberes. Enquanto metodologia de trabalho utilizamos as rodas de diálogo e as narrativas autobiográficas, como possibilitadoras de socialização, autorreflexão e (re)construções identitárias. A relação entre professores, professoras e estudantes da UFPE-CAA e moradoras, moradores do Alto do Moura, a partir desse trabalho educativo sinaliza para desconstrução de preconceitos.

Palavras-chave: Diferenças; Interseccionalidade; Educação.

\section{ABSTRACT}

This article results from an educational work by the "Ponto de Partida" group implemented in the Alto do Moura Community in Caruaru-PE. It refers to dialogues, reflections, and interventions about differences. We consider difference as a network of relationships to face inequalities configured from intersectional power

\footnotetext{
${ }^{1}$ Atualmente é Professora da Universidade Federal de Pernambuco/Centro Acadêmico do Agreste (UFPE/CAA). Doutora e Mestra em Educação pela Universidade Federal de Pernambuco. e-mail: maria.cgsantos@ufpe.br

${ }^{2}$ Atualmente é Professor da Universidade Federal de Pernambuco/Centro Acadêmico do Agreste (UFPE/CAA). Doutor em Educação pela Universidade Federal de Pernambuco. Mestre em Teologia pela Faculdade Jesuíta de Filosofia e Teologia. e-mail: everaldo.fernandes@ufpe.br
} 
structures involving gender, class, race, generation, and religion. The text presents the development of a university extension work that articulates subjects, training spaces, and knowledge. As part of the empirical study methodology, we used dialogue circles and autobiographical narratives as enablers of socialization, selfreflection, and identity (re)constructions. Based on this educational work, the relationship between teachers and students at UFPE-CAA and residents of Alto do Moura signals the deconstruction of prejudices.

Keywords: Differences; Intersectionality; Education.

\section{INTRODUÇÃO}

A diversidade pode ser tratada com um sentido celebratório, romantizado, colonizador, numa perspectiva liberal, que considera a pluralidade de maneira justaposta, sem referenciar as desigualdades, tampouco as relações de poder presentes entre sujeitos e grupos sociais.

Neste trabalho, as diversidades são anunciadas como forma de evidenciar as diversas expressões e vivências culturais, identitárias, estéticas e políticas de configurações humanas, que muitas vezes, passam a ser alvo de discriminação, preconceito e desigualdades. Desse modo, ao evocar as diversidades (classe, raça, gênero, sexualidade, etnia, geração, deficiência) provocamos o diálogo com a categoria da diferença, que ajuda a ressaltar as relações de poder, de violência que permeiam essas relações.

A diferença enquanto contradições sociais, como redes de relações (MCLAREN, 1997), denuncia as desigualdades, a ligação entre as diversas formas de discriminação e preconceito $^{3}$, entretanto, considera as possibilidades de intervenção e de "pontos de fuga" dos sujeitos.

Embora o diverso, o múltiplo, seja considerado, a tendência à essencialização dessa diversidade, como algo dado, pronto, promove um trato justaposto, que opaciza relações desiguais. A categoria da diferença contribui para "tirar a venda", favorece à compreensão desses meandros, seu anúncio e denúncia das formas de opressão (SANTOS, 2016).

\footnotetext{
${ }^{3}$ Discriminação neste trabalho é compreendida como formas de violências " [...] cometidas contra indivíduos por motivos diversos, possuem um forte componente de violência simbólica, e podem ser exercidas também pelo poder das palavras que negam, oprimem ou destroem psicologicamente o outro" (BRASIL, 2012). Para Rios (2009) o preconceito refere-se a percepções mentais e representações sociais negativas em relação a grupos inferiorizados, a discriminação é a materialização do preconceito nas relações sociais.
} 


\section{Revista \\ Debates Insubmissos}

O contexto social contemporâneo mobiliza estarmos atentos e atentas para toda forma de preconceito, de discriminação que classifica, machuca, desvaloriza e inferioriza sujeitos e suas produções culturais, econômicas e sociais. A herança histórica do nosso país, colonizado, racista, patriarcal, misógino e homofóbico interpela todas e todos a romper com o preconceito naturalizado, que encara essas desigualdades como imutáveis. Entretanto, nessa proposta o movimento é evidenciar as culturas, expressões e vivências silenciadas socialmente, numa perspectiva de empoderamento (individual e coletivo); por isso, distingue-se da ideia de empowerment (FREIRE; SHOR, 2011), porque enfatiza a coletividade, as alianças, os diálogos libertadores, na luta por justiça social (TORRES SANTOMÉ, 2013).

Com base nesta definição de diversidades e diferença apresentamos o projeto de extensão, compreendendo-as enquanto horizontalidade, diálogo, partilha de saberes, busca de alternativas mútuas, entre comunidade e universidade.

O projeto "Ponto de Partida: alimentando diálogos, reflexões e intervenções educativas no Alto do Moura, acerca das diversidades, numa perspectiva de diferenças" toma o "ponto de partida" no sentido do inacabamento, da incompletude, pois estamos sempre retomando, recomeçando e ressignificando, diante da condição humana e dos desafios que a interpelam (FREIRE, 2003). Por isso nos valemos da metáfora do alimento com o propósito de aprendizagens mútuas, que nos deem "sustança e sustento" no enfrentamento das injustiças sociais.

O projeto intenta momentos de partilha, nos quais os sujeitos, espaços e saberes se entrelaçam para se nutrir de esperança, projetos e ações, superando a ideia da extensão como comunicação. O ser humano, enquanto ser da práxis, tem a capacidade de refletir sobre e com o mundo, sobre suas ações e relações, sobretudo, no coletivo. A extensão, que se quer libertadora, não comunica, não manipula cultural e politicamente o outro, a outra; contribui através da dialogicidade, do respeito pelos saberes, da partilha da palavra (FREIRE, 1983). Para tanto, o cuidado com a linguagem simples, sem ser simplista; com a acolhida e a escuta respeitosa e atenta às demandas do grupo; com a tessitura de ensaios responsáveis e comprometidos politicamente; além do compromisso com os dissensos, permeiam a proposta. 


\section{Debates Insubmissos}

Revista

A intenção do projeto é refletir, dialogar e intervir contra o preconceito, a discriminação e injustiças sociais, evidenciando as diversidades, numa perspectiva de diferenças. Assim, situamos esse como um trabalho educativo, não necessariamente escolar, embora envolva a universidade e possa abarcar espaços, sujeitos e saberes da Educação Básica.

Definimos como objetivo geral dialogar e refletir sobre as diversidades, numa perspectiva de diferença, em vista da superação dos preconceitos e das discriminações. Para tanto, os objetivos específicos são: partilhar e ressignificar saberes, situando os desafios e possibilidades enfrentados pelos sujeitos para lidar com suas experiências, relativas às diversidades; além disso, intervir contra preconceitos e injustiças sociais, instigando o empoderamento das e dos sujeitos.

A intenção se aproxima das contribuições de Junqueira (2009) quando sugere que sejam criados espaços de fala, de reflexão para o trato às diferenças, sobretudo, em relação àqueles e àquelas que têm dificuldade em lidar com seus preconceitos.

O projeto conta com uma abordagem dialógica, que prima pela horizontalidade das relações, pela partilha de saberes e, sobretudo, pela reflexão crítica e pelo comprometimento político, voltados para a justiça social.

O campo principal de intervenção situa-se no município de Caruaru, mais precisamente no Alto do Moura, por ser um local de efervescência cultural, trocas de saberes e experiencias. Além disso, por ser um dos locais do município onde há relatos de famílias e sujeitos que sofrem com a discriminação e o preconceito, tendo em vista o ranço da cultura machista e patriarcal, com manifestações de LGBTfobia.

A narrativa, como possibilidade de socializar as experiências, que nos perpassam e instituem (LARROSA, 2002), vai para além do simples relato. As narrativas envolvem retomadas, revisões, ressignificações das histórias de vidas humanas, situadas em contextos, tempos e espaços. Além disso, podem provocar empatia, pois as vivências "da outra, do outro", também nos envolvem, nos convidam a relatar sobre nossas experiências. Entendemos 


\section{Revista \\ Debates Insubmissos}

que "A transmissão da experiência de vida implica uma interpretação narrativa de nós mesmos" (FONSECA, 2006, p.147), num sentido formativo.

O grupo "Ponto de Partida" criado em março de 2017 por pessoas da comunidade do Alto do Moura, lideranças, artistas, professoras e professores, teve a intenção inicial de discutir sobre LGBTfobia, devido aos relatos e fatos ocorridos na localidade. As reuniões mensais, realizadas a partir de narrativas, histórias de vidas de pessoas convidadas, leituras e interpretações de textos bíblicos, diálogos, projeção e análise de vídeos e textos da mídia provocaram outras demandas.

À medida que o grupo crescia outras demandas apareciam, dentre elas, a necessidade de ultrapassar a temática de gênero e sexualidade. Em agosto de 2017 o grupo decidiu abarcar as temáticas e vivências das diversidades que surgissem, tendo em vista que as questões de classe, raça, gênero, deficiência, sexualidade, etnia se perpassam. Ao invés do "modelo associativista" que soma, justapõe ou hierarquiza uma categoria em relação a outra, inclusive, aplicando uma somatização de desvantagens e uma perspectiva determinista (ROSEMBERG, 2006) dizemos que as diversidades se entrelaçam, interpelam, interseccionam.

Os sujeitos que se comprometem a se libertar dos próprios preconceitos ou lutar contra os preconceitos vivenciados/visualizados não fazem distinção do "tipo" de preconceito. Não há como mensurar, classificar, definir níveis de intensidade, em relação às diversas dores, decorrentes das discriminações. Por isso compreendemos que "[...] seria igualmente insuficiente; as opressões não podem ser sumariamente, classificadas, relacionadas causalmente, e distribuídas entre planos pretensamente correspondentes ao que é 'original' e ao que é "derivado" (BUTLER, 2013, p. 34). Assim, o projeto "Ponto de Partida" enseja trabalhar com as diversidades, nas suas (inter)relações e inter(faces). 


\section{FUNDAMENTAÇÃO TEÓRICA}

A relação entre ensino, pesquisa e extensão mobiliza o diálogo entre espaços, sujeitos e saberes. Desse modo, situamos a extensão numa perspectiva dialogal, que demanda escuta, reflexão e diálogo, sobretudo porque a compreensão de conhecimento que orienta este trabalho ultrapassa o paradigma da ciência moderna, tomada na sua acepção clássica, objetiva, neutra, universal e distante da realidade.

O trabalho está pautado na Resolução N. 09/2017, que regulamenta a inserção e o registro da Ação Curricular de Extensão (ACEx) como carga horária nos projetos pedagógicos de cursos de graduação da Universidade Federal de Pernambuco:

Compreende-se a Extensão Universitária como um processo interdisciplinar, educativo, cultural, científico e político, que integra a formação acadêmica profissional e cidadã do discente, e promove a relação transformadora entre a universidade e outros setores da sociedade (PERNAMBUCO, 2017).

Através desse processo articulado, comprometido e transformador a extensão na Comunidade do Alto do Moura visa o intercâmbio de saberes entre docentes, discentes e comunidade, com foco na discussão sobre as diferenças.

A extensão na comunidade do Alto do Moura preza pelos conhecimentos/saberes do cotidiano das pessoas em situação de discriminação, de subalternização, uma vez que todo conhecimento é autoconhecimento (SANTOS, 2010) e essas experiências podem produzir novas reflexões sobre si e sobre o outro, a outra, alternativas e novos caminhos.

A ciência moderna ao supervalorizar o universal em detrimento do conhecimento local, elege lugares, sujeitos, métodos e referentes como verdadeiros e inquestionáveis. Esses referentes, geralmente são ocidentais, eurocêntricos, brancos, heterossexuais e masculinos, fora desse padrão estão os conhecimentos, sujeitos e locais marginalizados, questionados e descredibilizados.

Essa subalternização acontece, sobretudo, com os conhecimentos dos povos originários, das mulheres, das e dos LGBTs, das e dos quilombolas. A subalternização ocorre de várias maneiras, na invizibilização da produção realizada por esses sujeitos nos vários campos do conhecimento, como por exemplo, nos livros didáticos, na literatura, na validação 
de prêmios. Embora esses sujeitos e suas produções ainda sejam negados, eles e elas produziram, resistiram e contribuíram com a ciência, a exemplo dos movimentos e literatura feminista (ALMEIDA, 1998, HARDING, 1993, LAGE, 2008, MCGRAYNE, 1994).

O silenciamento desses sujeitos, saberes e locais dizem dos interesses em preservar as estruturas e relações coloniais, patriarcais, heterossexuais que orientam países de herança colonizada. A ideia é que não haja ideias (no plural), que relações hierárquicas, verticalizadas e servis se perpetuem, por isso, o "plano" de tentar ridicularizar, fragilizar, questionar os conhecimentos e alternativas que fogem à norma. Para Lage:

O conjunto desta pluralidade tem reivindicado, com legitimidade espaços de articulação entre saberes que possibilitem configurações mais democráticas, que ampliem as possibilidades de diálogos e reconhecimentos. A luta cria um permanente embate epistemológico muitas vezes desigual, pois ocorre entre esferas de poder consolidadas pelos históricos processos de dominação frente aos outros conhecimentos (LAGE, 2008, p. 205).

A escuta atenta, respeitosa e pedagógica de saberes/conhecimentos subalternizados, no sentido da partilha de conhecimentos e construção de aprendizagens, pode gerar alternativas de vida, de sobrevivência, de luta e trabalho menos oprimidas, vigiadas e limitadas. Essa tomada de consciência, que envolve o movimento não linear que mobiliza a consciência intransitiva (ausência de reflexão), a consciência ingênua (explicações limitadas) até alcançar a consciência crítica (FREIRE, 2008) incomoda as estruturas de poder, de dominação que, por muito tempo manipularam os campos do conhecimento, das ciências, das produções. Por isso a importância da educação crítica, em espaços escolares e não escolares, em vista da superação da condição de intransitividade, face a transitividade crítica.

A transitividade crítica por outro lado, a que chegaríamos com uma educação dialogal e ativa, voltada para a responsabilidade social e política, se caracteriza pela profundidade na interpretação dos problemas. Pela substituição de explicações mágicas por princípios causais. Por procurar testar os 'achados' e se dispor sempre a revisões. Por despir-se ao máximo de preconceitos na análise dos problemas e, na sua apreensão, esforçar-se por evitar deformações. Por negar a transferência de responsabilidade [...] (FREIRE, 2008, p. 69).

A extensão, comprometida com a formação crítica dos sujeitos acolhe, abarca e valoriza a pluralidade de saberes/conhecimentos, no exercício de superação de discriminações, de explicações superficiais e prontas, de manipulações midiáticas. Desse 


\section{Revista
Debates Insubmissos}

modo, o projeto formativo extensionista, na interação entre universidade e comunidade supera a proposta de comunicação, a partir de uma relação, informativa, linear, direcionada de um “centro" para uma "margem". O movimento é dialogal, horizontalizado, de troca de saberes/conhecimentos e busca de alternativas (FREIRE; SHOR, 2011).

Numa perspectiva interseccional articulamos as dimensões das diferenças (classe, raça, gênero, sexualidade, etnia, geração, religião, região), bem como, diversas áreas dos saberes (saúde, educação, segurança, habitação) enquanto abordagem teórico-metodológica, a fim de não sobrepormos as diferenças, hierarquizando-as. A interseccionalidade também possibilita buscarmos alternativas em várias frentes de luta para o enfrentamento das desigualdades.

Desse modo, o conceito de interseccionalidade, inspirado no feminismo negro dos anos de 1970, enquanto interdependência das relações de poder que atravessam raça, sexo e classe, como denuncia Daves (2016); também como uma proposta para lidar com as "múltiplas fontes de identidade", também evidencia a não hierarquização das formas de opressão (HIRATA, 2014). Com o cuidado de considerar as demandas, especificidades e frentes de luta de cada grupo/movimento, possibilita o suporte teórico-metodológico para o enfrentamento da aliança estrutural entre racismo, patriarcado e capitalismo (AKOTIRENE, 2019)

O trabalho educativo, numa perspectiva interseccional valoriza as histórias de vida, considerando os marcadores das diferenças, presentes nas relações de poder. Nessa perspectiva, as dores vivenciadas e relatadas pelos sujeitos não são sobrepostas, tampouco quantificadas em níveis de "mais ou menos dor", são considerados como experiências que marcam vidas e possibilitam superações.

Conforme sinaliza Santos (2016) a presença do trabalho educativo com as diferenças, entre elas, de gênero e de sexualidade contribui para a superação dos preconceitos e das discriminações. O desafio dessa superação diz da necessidade de um trabalho articulado entre sujeitos, saberes e instituições. 


\section{Revista \\ Debates Insubmissos}

As ações de extensão, voltadas para a educação comunitária, refletem o nível de compromisso e a capacidade crítica e criadora das pessoas e das/dos educadoras/es preocupadas/dos com um novo momento histórico e com um novo desejo de sociedade. Essa preocupação e esse desejo existem porque, junto às ações de extensão, prospectamos também esperança nas crianças, nos/as jovens, adultos/as, educandos/as e educadores/as, pessoas das comunidades com os/as quais partilhamos nossas ideias e ações. Freire (2009, p.11) nos fortalece quando fala de esperança, dizendo que

Sem um mínimo de esperança não podemos sequer começar o embate mas, sem o embate, a esperança, como necessidade ontológica, se desarvora, se desendereça e se torna desesperança que, às vezes, se alonga em trágico desespero. Daí a precisão de uma certa educação da esperança. É que ela tem uma tal importância em nossa existência, individual e social, que não devemos experimentá-la de forma errada, deixando que ela resvale para a desesperança e o desespero.

Percebemos que a desesperança e o desespero acontecem quando os/as sujeitos/as se veem sozinhos/as, isolados/as, em suas lutas e embates. A ação em conjunto, respaldada na parceria, no envolvimento dos grupos, dá sentido à espera, à esperança; e combate o desânimo que nos acomete de vez em quando, diante de situações de difícil enfrentamento na vida cotidiana, nos espaços comunitários. Estas situações-limite (FREIRE, 2009), requerem uma nova compreensão sobre a concepção de autonomia, que, no dizer de Gohn, é

[...] fundamentalmente, ter projetos e pensar os interesses dos grupos envolvidos com autodeterminação... é ter a crítica, mas, também a proposta de resolução para o conflito em que estão envolvidos, é ser flexível para incorporar os que ainda não participam, mas têm o desejo de participar, de mudar as coisas e os acontecimentos da forma como estão... ter autonomia é priorizar a cidadania: construindo-a onde não existe, resgatando-a onde foi corrompida (GOHN, 2013, p. 239).

A intenção do projeto, em desenvolvimento desde março de 2017 é refletir, dialogar e intervir contra o preconceito, a discriminação e injustiças sociais, evidenciando as diversidades, numa perspectiva de diferenças. 


\section{AS RODAS DE DIÁLOGOS E AS NARRATIVAS AUTOBIOGRÁFICAS NO ALTO DO MOURA}

A metodologia de um projeto diz da sua natureza, princípios e caminho de efetivação, que parte de escolhas e expressa a função social, o desejo e mecanismos de intervenção social. Nesse caso, a metodologia utilizada pelo grupo é a roda de diálogos, geralmente coordenada por professores e professoras da Universidade Federal de Pernambuco, do Centro Acadêmico do Agreste e por lideranças comunitárias do Alto do Moura. Os encontros ocorrem mensalmente, na residência de uma líder comunitária e é aberta a todos e todas que se interessam em participar das reuniões.

Os encontros são temáticos, a partir das demandas da comunidade e há sugestões/indicações de convidado, convidada envolvido com o tema. Desse modo, profissionais das diversas áreas, representantes de movimentos sociais, de ONGs partilham suas experiências.

Algumas das temáticas abordadas pelo grupo tratam de questões de gênero, raça, classe, etnia, região, religião, geração e articulam áreas do saber que se entrecruzam, saúde, educação, moradia, segurança. A proposta persegue a interseccionalidade enquanto estratégia articulada de enfrentamento das desigualdades estruturais, promovidas pelas várias formas de preconceitos (classe, raça, etnia, geração, religião, gênero e sexualidade).

Para tanto, são realizados encontros acerca de desigualdade de gênero, homossexualidade e religião, LGBTfobia e relações familiares, pessoas surdas, atuação dos e das vereadores(as), vereadoras no município, saúde das populações indígenas, preconceito contra pessoas tatuadas, artistas de rua, deficiência visual, cadeirantes e acessibilidade, violência obstétrica, adoção.

As narrativas autobiográficas, em muitas situações são utilizadas, como forma de os sujeitos socializarem suas experiências, rememorando fatos vividos, trazendo sentimentos que, muitas vezes, são retrabalhados com a ajuda do grupo. A narrativa autobiográfica possibilita situar o contexto cultural dos sujeitos, envolve a experiência, enquanto categoria 
que nos constitui e perpassa, dizendo da sua historicidade e da (re)construção identitária. As narrativas envolvem processos de autorefexão e formação, pois “[...] compreendem um processo de intervenção livre e criativo sobre o real problemático e problematizador" (FONSECA, 2006, p.158)

A projeção e análise de vídeos, bem como, leitura e discussões de textos contribuem para a "educação do olhar" no sentido de refletir criticamente acerca das imagens, das histórias narradas, dos cenários.

O momento de chegada de cada participante do grupo é tratado enquanto acolhida e afeto, onde cada um, cada uma traz um prato de comida preparado com a intenção de alimentar, reunir e partilhar saberes e sabores. A criação de um grupo de WhatsApp viabiliza a logística do encontro. Esse grupo virtual também auxilia na socialização de vídeos, links de textos e reportagens que contribuem com o trabalho educativo, através de debates e comentários dos e das participantes.

Além dos encontros realizados mensalmente na comunidade do Alto do Moura com o grupo "Ponto de Partida", iniciamos articulações com o grupo das mulheres do Alto do Moura; bem como, com a Biblioteca Comunitária, a fim de ampliar e intensificar as discussões acerca das diferenças. Componentes do grupo participaram da III Festa Literária do Alto do Moura, ofertando palestras, minicursos e oficinas educativas.

\section{CAMPO E SUJEITOS}

O Alto do Moura, a aproximadamente $5 \mathrm{~km}$ do marco zero do município de Caruaru, é um importante polo cultural, artístico e também turístico do estado de Pernambuco e do Brasil, com uma população de 2.400 (dois mil e quatrocentos) habitantes, em sua maioria, ceramistas que participam de todo o processo produtivo da arte (da coleta do barro à comercialização e envio das peças) ${ }^{4}$.

\footnotetext{
${ }^{4}$ Disponível em: <http://cidades.ibge.gov.br/xtras/temas.php?lang=\&codmun=260410\&idtema=16\&search $=\|$ síntese-das-informações $>$. Acesso em: 15 maio 2014.
} 


\section{Debates Insubmissos}

Revista

No Alto do Moura estão localizados a casa-museu de Vitalino e o memorial de Luiz Galdino, importantes representantes das artes figurativas do barro, além de casas/oficinas de moradoras e moradores da localidade que produzem suas artes, expõem e comercializam. A comunidade se organiza coletivamente através da Associação dos Artesãos do Alto do Moura (ABMAM), criada na década de 1980 para defender e lutar por direitos profissionais e sociais dessa comunidade. A cultura também é vivenciada através da música e da dança que expressam as influências cristãs (reisado), indígena (mazurca) e portuguesa (pastoril), onde participam mulheres e homens (SILVA, 2011).

A comunidade do Alto do Moura se organiza de forma coletiva também em grupos de mulheres, que se reúnem semanalmente para tratar de questões dos seus cotidianos pessoais e profissionais, e envolvem as dimensões de gênero, de raça, de classe, de religião e geração. Assim como, existe o grupo de idosas, idosos para tratar das suas demandas específicas, que envolvem também as questões geracionais. Há grupo de mulheres artesãs, criado com a intenção de preservar a arte do barro, o Flor do Barro foi criado em 2014 e hoje produz e comercializa coletivamente suas peças, oferece cursos e se organiza politicamente em defesa dos interesses das artesãs. Há grupos religiosos que, além de professar sua fé, atuam em comunidades em situação de pobreza, refletindo criticamente sobre as condições sociais locais. Nas reuniões do "Ponto de Partida" sempre há presença de representantes desses grupos, que realizam a interconexão entre suas discussões.

O sentimento de coletividade presente na Comunidade do Alto do Moura materializase na relação de parentela, para além da consanguinidade, pois o cuidado entre as pessoas, a proximidade, a afetividade (afetos positivos e negativos) e a colaboração fazem parte do cotidiano dessa grande família. Há uma unidade na diversidade que permite as trocas culturais, as resistências e a sobrevivência humana e artística.

O Campus Acadêmico do Agreste também tem as suas especificidades. Foi primeiro campus da UFPE inaugurado em março de 2006, fruto do programa de interiorização das universidades públicas federais. Com o objetivo de contribuir com o desenvolvimento econômico, social e político de Pernambuco. 
O CAA vem suprir a necessidade de ensino gratuito e de qualidade na região, visto que há cursos superiores já instalados, em sua maioria oferecidos por instituições privadas. O Centro iniciou suas atividades com cinco graduações, nas áreas de Administração, Economia, Engenharia Civil, Pedagogia e Design, que integram quatro Núcleos de Ensino (Gestão, Design, Formação Docente e Tecnologia). Atualmente, funcionam também as licenciaturas em Química, Física e Matemática, o curso de Engenharia de Produção e a Licenciatura Intercultural, direcionada à população indígena de Pernambuco ${ }^{5}$.

O CAA possibilita a formação profissional em diversas áreas do saber, favorece o desenvolvimento socioeconômico, cultural e político de estudantes e da própria região. Considerando que o Campus se situa em local campesino, destacamos também a aproximação de professores e professores e estudantes da localidade do campo; além de favorecer à construção e ressignificação de Representações Sociais sobre o interior e sobre o campo, à intervenção nessa realidade.

A universidade pública em Caruaru pode contribuir com a possibilidade de a formação perseguir a educação laica, liberta de determinações religiosas e colonialistas, muitas vezes presas a padrões racistas, heteronormativos e binários de gênero.

Embora ainda não tenhamos realizado pesquisa sobre as repercussões do Projeto Ponto de Partida na comunidade do Alto do Moura, há registros de observações e falas que apontam para desafios e conquistas desse projeto.

\section{DESAFIOS E CONQUISTAS COMO PRIMEIRAS CONSIDERAÇÕES}

Enquanto componentes do grupo, desde a sua formação, a partir da observação e registros em diário de campo, podemos sinalizar para alguns desafios e conquistas realizadas ao longo desses três anos de trabalho.

A formação de um grupo para discutir as diferenças configura-se como um dos maiores desafios, sobretudo, nesse contexto de desigualdades e de preconceitos, intensificado com as cruzadas morais que tentam reter as conquistas das chamadas minorias (MISKOLCI, 2018). Em relação à dimensão local, despertar na comunidade o interesse em participar de um

\footnotetext{
${ }^{5}$ Disponível em: <https://www.ufpe.br/caa/index.php?option=com_content\&view=article\&id=55\&Itemid=71>. Acesso em: 05 out. 2015.
} 


\section{Revista
Debates Insubmissos}

processo educativo, tratando das questões das diferenças, para nós é o grande desafio; além de manter a presença da comunidade nas reuniões ao longo desses anos.

Prospectamos também a articulação entre os grupos existentes no Alto do Moura; sobretudo, o grupo das mulheres, tendo em vista a dimensão da intersecção entre classe, raça e gênero presente na tessitura dessas vidas. A intenção é a presença de mais componentes do "Ponto de Partida", de modo a estabelecer intercâmbios educativos, em vista do fortalecimento coletivo.

Envolver mais estudantes da Universidade Federal de Pernambuco nesses encontros faz parte dos objetivos desse projeto e diz da sua face desafiadora, relativa às políticas públicas no cenário atual. Em um contexto de cortes de bolsas, de sucateamento das universidades públicas, de ameaça à autonomia universitária, manter a presença de professores, professoras e estudantes nos encontros ultrapassa a dimensão de responsabilidade e do compromisso socioprofissional e político. Essa realidade se intensifica ao levarmos em conta a condição socioeconômica das e dos estudantes, que precisam de recursos para deslocamento e alimentação para passar o dia em Caruaru, tendo em vista que a maior parte deles e delas reside em outros municípios.

Contribuir com reflexões que alcancem transformações nas concepções, relações e práticas dos sujeitos, no que se refere a preconceitos, discriminações e desigualdades, ao mesmo tempo que pode ser apontada como desafio, já sinaliza para algumas conquistas, tendo em vista posturas de mais abertura para a escuta, a fala e a aproximação física entre sujeitos. Alguns relatos de participantes já indicam algumas superações de preconceitos relativos a gênero, sexualidade, tatuagem, deficiências. Para tanto, realizaremos investigação para reunir e analisar esses registros.

Outra conquista diz da aproximação entre sujeitos, saberes e espaços, no que se refere à horizontalização das relações, construções de diálogos abertos, compreensíveis e engajados politicamente. A persistência do grupo faz-se necessária, sobretudo, por compreendermos que as transformações das relações de opressão e discriminação não se dão apenas a partir de um movimento exógeno, por meio das discussões, estudos e provocações realizadas pelo grupo. 
A permanência na situação de dor, de discriminação e de opressão vai para além da libertação política e econômica; envolve memórias afetivas e sentimentos entranhados nas subjetividades, que demandam mais investimento do trabalho educativo, mais tempo para "maturar as ideias" e uma rede de apoio que auxilie na libertação.

Sozinhos, sozinhas, com o reforço das construções sociais homens e mulheres dificilmente percebem que reproduzem machismos, misoginia, racismo, discriminações. Como também, não se percebem enquanto vítimas desse sistema opressor, que através dos discursos e práticas naturaliza as violências. Para tanto, o trabalho de extensão atrai a pesquisa sobre os alcances e limites do Ponto de Partida na Comunidade do Alto do Moura.

\section{REFERÊNCIAS}

AKOTIRENE, Carla. Interseccionalidade. São Paulo: Pólen, 2019.

ALMEIDA, Jane Soares de. Mulher e educação: A paixão pelo possível. São Paulo: Fundação Editora da UNESP, 1998.

BUTLER, Judit. Problemas de gênero: feminismo e subversão da identidade. Tradução Renato Aguiar. 5. ed. Rio de Janeiro: Civilização Brasileira, 2013.

BRASIL. Secretaria Especial de Direitos Humanos. Relatório sobre violência homofóbica no Brasil: ano de 2012. Brasília, 2012.

DAVES, Angela. Mulheres, raça e classe. Tradução Heci Regina Candiani. São Paulo: Boitempo, 2016.

FONSECA, Selva Guimarães. Aprender a contar, a ouvir, a viver: as narrativas como processo de formação. In: FONSECA, Selva Guimarães (Org.). Técnicas de Ensino: Novos tempos, novas configurações. Campinas, SP: Papirus, 2006.

Freire, Paulo. Extensão ou comunicação? tradução de Rosisca Darcy de Oliveira Prefácio de Jacques Chonchol $7^{\mathrm{a}}$ ed. Rio de Janeiro, Paz e Terra, 1983. (O Mundo, Hoje, v. 24)

FREIRE, Paulo. Pedagogia da autonomia: saberes necessários à prática educativa. 26. ed. São Paulo: Paz e Terra, 2003. (Coleção Leitura).

FREIRE, Paulo. Pedagogia da Esperança. 16. ed. São Pulo: Paz e Terra, 2009. 
FREIRE, Paulo; SHOR, Iria. Medo e ousadia: o cotidiano do professor. 13 ed. São Paulo, 2011.

GOHN, Maria da Glória. Educação não formal e o educador social: atuação no Desenvolvimento de projetos sociais. São Paulo: Cortez, 2010. (Coleções questões da nossa época; v.1)

GOHN, Maria da Glória. Sociedade Civil no Brasil: movimentos sociais e ONGs. In: Meta: Avaliação | Rio de Janeiro, v. 5, n. 14, p. 238-253, mai./ago. 2013 Disponível em: http://revistas.cesgranrio.org.br/index.php/metaavaliacao/article/viewFile/145/pdf Acesso em: $30 / 06 / 2016$

HARDING, Sandra. A instabilidade das categorias analíticas na teoria feminista. Revista de Estudos Feministas. Florianópolis, Ano 1, $1^{\circ}$ semestre. 1993.

HIRATA, Helena. Gênero, classe e raça Interseccionalidade e consubstancialidade das relações sociais. Tempo soc., São Paulo, v. 26, n. 1, p. 61-73, June 2014. Available from $<$ http://www.scielo.br/scielo.php?script=sci_arttext\&pid=S0103-

$20702014000100005 \& \operatorname{lng}=$ en\&nrm $=$ iso $>$. access

on 01 Mar. 2020. https://doi.org/10.1590/S0103-20702014000100005.

LAGE, ALLENE. Pesquisa de campo em educação: Roteiros, narrativas e dilemas científicos In: GUIMARÃES; Orquídea Maria de Souza; SILVA, Jaqueline Barbosa. Pesquisa em Educação: teorias, experiencias e orientações. Recife: Ed. UFPE, 2018. (Coleção Livro Texto 2018).

LARROSA, Jorge Bonía. Notas sobre a experiência e o saber de experiência. Tradução de João Wanderley Geraldi. Revista Brasileira de Educação. Rio de Janeiro, n. 19, Jan./Apr. 2002.

MCGRAYNE, Sharon Bertsch. Mulheres que ganharam o prêmio Nobel em Ciências: suas vidas, lutas e notáveis descobertas. Tradução Maíza f. Rocha e Renata Brant de Carvalho. São Paulo: Marco Zero, 1994.

MCLAREN, Peter. Multiculturalismo crítico. Tradução Bebel Orofino Schaefer. São Paulo: Cortez, 1997.

MISKOLCI, Richard. Exorcizando um fantasma: os interesses por trás do combate à "ideologia de gênero". In: A construção do pânico moral da criança sob ameaça. In:

Cadernos Pagu. N. 53. 2018

PERNAMBUCO. Resolução 09/2017. Regulamenta a inserção e o registro da Ação Curricular de Extensão (ACEx) como carga horária nos Projetos Pedagógicos de Cursos de Graduação da UFPE. Recife, 2017.

RIOS, Roger Raupp. Homofobia na perspectiva dos Direitos Humanos e no Contexto dos Estudos sobre preconceito e discriminação. In: (Org). Diversidade Sexual na Educação: problematizações sobre homofobia nas escolas. Brasília: Ministério da Educação, Secretaria de Educação Continuada, Alfabetização e Diversidade, UNESCO, 2009. 
ROSEMBERG, Fúlvia. Educação Formal, mulher e gênero no Brasil Contemporâneo. In: MELO, Hildete Pereira de; PISCITELLI, Adriana; MALUF, Sônia Weidner; PUGA, Vera Lucia (Orgs.). Olhares feministas. Brasília: Ministério da Educação: UNESCO, 2006. 510 p. (Coleção Educação para Todos; v. 10). Disponível em:

$<$ http://portal.mec.gov.br/index.php?option=com_content\&id=13529:colecao-educacao-paratodos>. Acesso em: 02 fev. 2014.

SANTOS, Boaventura de Souza. Um discurso sobre as ciências. 7. ed. São Paulo: Cortez, 2010.

SANTOS, Maria do Carmo Gonçalo. As contribuições do currículo da formação para a prática pedagógica docente com gênero e sexualidade na educação básica. 2016. $400 \mathrm{fl}$. Tese (Doutorado em Educação). Universidade Federal de Pernambuco. Recife, 2016.

SILVA, Everaldo Fernandes da. Processos aprendentes e ensinantes dos/as artesãos/ãs do Alto do Moura: tessitura de vida e formação. 2011. 278f. Tese (Doutorado em Educação) Universidade Federal de Pernambuco, Recife, 2011.

TORRES SANTOMÉ, Jurjo. Currículo escolar e justiça social: o cavalo de Troia da educação. Tradução: Alexandre Salvaterra; revisão técnica: Álvaro Hypolito. Porto Alegre: Penso, 2013.

Recebido: 09/07/2021

Aprovado: 30/12/2021 